\title{
THE USE OF BUCCAL ANTROSTOMY BONE AS A GRAFT FOR CLOSURE OF ORO- ANTRAL FISTULA
}

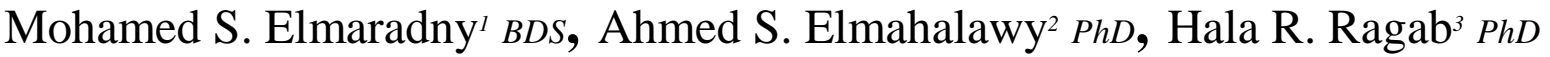

\begin{abstract}
INTRODUCTION: Oroantral fistula is an epithelialized, pathological and unnatural communication between the oral cavity and the maxillary sinus.

OBJECTIVES: The aim of this study was to evaluate the use of buccal antrostomy bone as a graft for closure of oroantral fistula clinically and radiographically.

MATERIALS AND METHODS: A prospective study was done on 10 patients complaining of oroantral fistulae following extraction of maxillary posterior teeth.

The bony defect of the oroantral fistula was closed by anterior wall of maxillary sinus as a graft material and fixed to the surrounding bone using N-Butyl-2-Cyanoacrylate (Histoacryl ${ }^{\circledR}$ ), then covered by buccal advancement flap.

The patients were followed up clinically after 4, 6, 8 and 12 weeks postoperatively

Radiographic evaluation was performed by cone beam computed tomography (CBCT) preoperatively and after 12 weeks postoperatively.

RESULTS: Evaluation of the patients revealed that proper healing of the wound occurred in most of the patients except in 3 patients whose bone graft was exposed and removed.

Radiographicaly, significant amount of bone was formed comparing the preoperative and postoperative CBCT of the patients.

CONCLUSIONS: According to the results of the present study, it is concluded that the use of the buccal antrostomy wall as a bone graft fixed with $\mathrm{N}$ butyl cyanoacrylate proved successful results in closure of large oroantral fistula.

KEYWORDS: Oroantral fistula, anterior wall of maxillary sinus, N-Butyl-2-Cyanoacrylate (Histoacryl®).

1- BDS, MS, Alexandria University, Faculty of Dentistry, Alexandria University, Egypt.

2- Professor at Department of Oral and Maxillofacial Surgery, Faculty of Dentistry, Alexandria University, Egypt

3- Assistant Professor at Department of Oral and Maxillofacial Surgery, Faculty of Dentistry, Alexandria University, Egypt.
\end{abstract}

Corresponding author:

E-mail: mohamedsaeed45@gmail.com

\section{INTRODUCTION}

Oroantral fistula is a clinical complication which is frequently encountered by oral surgeons. The incidence of this complication varies from $0.31 \%$ to $3.8 \%$ after simple extraction of the related maxillary teeth (1).

Oro-antral fistula is an epithelialized communication that develops between the pseudostratified columnar ciliated epithelium of the maxillary antrum and squamous epithelium of the oral mucosa (2).

Oro-antral fistula most commonly occurs as a complication of maxillary molar or premolar extraction. The primary reason is the anatomic proximity of the root apices to the sinus floor or projection of the roots into the maxillary sinus. Other causes of oro-antral fistula include dentoalveolar infections and destruction of a portion of the sinus by cysts or benign or malignant tumors and trauma (2).

In the absence of sinus infection, most small acute oroantral communications, $1-3 \mathrm{~mm}$ in diameter will heal spontaneously after the formation of a blood clot and secondary healing. However, larger oroantral defects that are not diagnosed or left untreated rarely heal, and the subsequent formation of an oroantral fistula requires secondary surgical closure (2).

Treatment modalities for repairing the oroantral fistula include local soft tissue flaps, with or without autogenous grafts or alloplastic materials. The most common techniques used are: buccal flap, palatal flap, and buccal pad fat flap, each has both advantages and disadvantages (2).

Proctor (3) first suggested bone grafts harvested from the iliac crest for closure of large oroantral communications in 1969. Nevertheless, bone grafting for closure of oroantral communications has the disadvantage of requiring a second surgical procedure for bone harvesting. This second procedure elongates surgical time and increases patient morbidity. Despite these disadvantages, bone grafting for closure of oroantral communications has gained attention over the past years, because of the rising demand for implant rehabilitation.

Harvesting bone from the iliac crest involves significant donor site morbidity, like prolonged post-operative pain and possible sensory disturbance (4). Moreover, harvesting bone from intra-oral donor area significantly reduces the demands made on the patients postoperatively and can be performed under local anesthesia (5). Therefore, alternative donor areas have been investigated, including bone grafts from the retromolar area, zygomatic process and the chin. Watzak et al in 2005 (6) harvested retromolar bone for press- fitted closure of oroantral communications in 4 patients. After placing the bone graft, soft tissue closure was done by means of a Rehrmann buccal advancement flap. No re-opening of the sinus was observed (7).

A restraining factor of the retromolar donor area is the limited amount of bone available (6). However, in most 
cases only a small amount of bone will be needed for closure of oroantral communications. Besides, retromolar bone seems to form a solid base for implant rehabilitation (6).

Different methods were suggested for fixation of the bone grafts to give it more stabilization. Cyanoacrylates are a family of strong fast-acting adhesives with industrial, medical, and household uses. Cyanoacrylate adhesives have a short shelf life if not used, about one year from manufacture if unopened, and one month once opened. They have some minor toxicity(8).

Among the synthetic glues, the N-Butyl-2Cyanoacrylate (Histoacryl ${ }^{\circledR}$ ), might find interesting application in the fixation of the bone graft due to its high adhesive, hemostatic properties, high biocompatibility and slow resorption without foreign body reaction $(8,9)$.

In this study, buccal antrostomy (caldwell-luc) (10) was done and used as a bone graft for closure of the oroantral fistulae and fixed by N-butyl cyanoacrylate (Histoacryl ${ }^{\circledR}$ ), then covered by buccal advancement flap as a double layer closure.

\section{MATERIALS AND METHODS}

Appropriate ethical clearance was obtained from the Faculty of Dentistry, Alexandria University, and an informed consent was obtained from the participant patients.

\section{I.Criteria of Patient Selection}

A prospective study was conducted on a total number of 10 patients suffering from oroantral fistulae. All patients were selected, and operated in the Oral and Maxillofacial Surgery Department, Faculty of Dentistry, Alexandria University, Egypt.

\section{Inclusion criteria:}

Long standing oroantral fistula caused by extraction of upper posterior teeth and patients with fistula equal to or larger than $5 \mathrm{~mm}$ of the clinical widest diameter.

\section{Exclusion criteria:}

Medically compromised patients who were not fit for surgery, fistulae that were smaller than $5 \mathrm{~mm}$ in size and fistulae that were secondary to other causes (e.g trauma or cyst).

\section{Materials}

1. Piezotome

2. A number 11 scalpel blade.

3. A number 15 scalpel blade.

4. (3-0) Vicryl suture material

5. N-Butyl-2-cyanoacrylate (Histoacryl ${ }^{\circledR}$ )

Histoacryl ${ }^{\circledR}$ is an n-butyl-2-cyanoacrylate tissue adhesive comes in $0.5 \mathrm{ml}$ plastic ampoule with blue colour (manufactured by B. Braun surgical, S.A Carretera de Terrassa, 12108191 Rubi, Spain).The vial was squeezed and applied to fix the bone graft to the bony defect of the fistula.

\section{Method}

\section{1- Pre-Operative evaluation}

\section{a)Clinical examination}

Patients who were complaining of regurgitation of food and fluids from the nose on the affected side after dental extraction, blunt probe was used for clinical examination of the fistulae.
Cone beam CT (CBCT) was done preoperatively to assess the size of the bone defect, then done 12 weeks postoperatively to assess the amount of bone formation.

\section{c) Preoperative preparation}

In long standing oro-antral fistulae associated with maxillary sinus infection and purulent discharge, the affected sinus was irrigated daily with antiseptic mouthwash through the fistula and the patient was given broad spectrum antibiotic in the form of Amoxicillin 875 mg/ clavulanic acid $125 \mathrm{mg}$ (Augmentin1gm: GSK GlaxoSmitheKline, England) one tablet every 12 hours for seven days until the infection resolved to reduce the risk of field contamination.

\section{2-Surgical procedure:}

Operation was done under general anesthesia. First,preoperative photo was taken for the fistula (Figure 1). Then,local anesthesia infiltration at the buccal vestibule with Mepivacaine (Mepacaine-L $1.8 \mathrm{ml}$ carpule manufactured by :Alexandria co for pharmaceuticals, Alexandria, Egypt) as a vasoconstrictor at the surgical site was done to obtain clear field. Then, excision of the fistulous tract using surgical scalpel blade no11 was done. After that, vestibular incision was done using blade no 15 and buccal advancement mucoperiosteal flap elevation. Refreshment of the bony edges using bone file, then Caldwell-Luc procedure was done. An area of anterior maxillary sinus wall at the canine fossa was outlined with methylene blue dye according to the fistula dimensions and the piezotome (Figure 2) was used to harvest the buccal antrostomy bone for grafting. (Figure 3) After that, the graft outlined for harvesting was well marked away from maxillary teeth apices, pyriform aperture and infraorbital foramen to avoid inadvertent trauma to these vital structures. The infected lining of the maxillary sinus was removed and irrigation of the maxillary sinus was carried out with copious saline wash. Then, the bone graft was press fitted into the defect and fixed by $\mathrm{N}$-Butyl cyanoacrylate (Histoacryl ${ }^{\circledR}$ ) (Figure 4) and the buccal flap was repositioned and advanced to be sutured with palatal mucosa without tension. Finally, the periosteum padding the flap was incised horizontally at the base of the flap to allow advancement of the flap. (Figure 5)

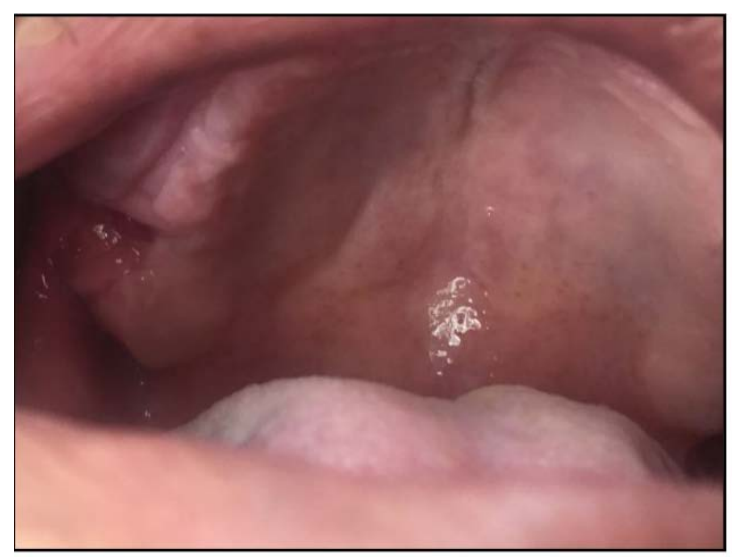

Figure (1): Preoperative picture of right maxillary OAF following extraction of right maxillary second molar tooth.

\section{b)Radiographic Examination}




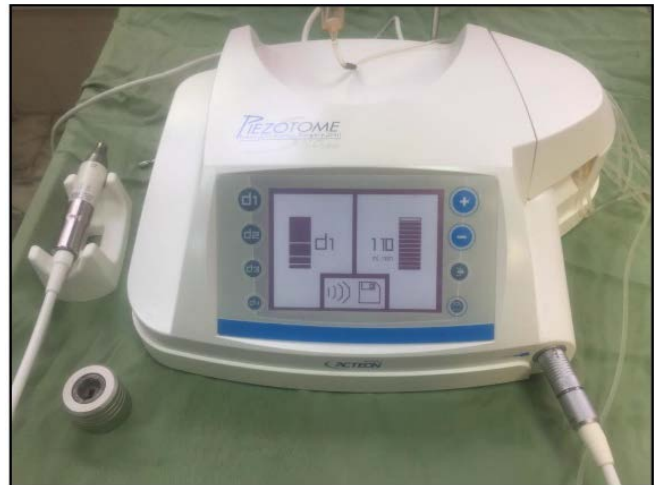

Figure (2): Piezotome used for harvesting the bone graft.
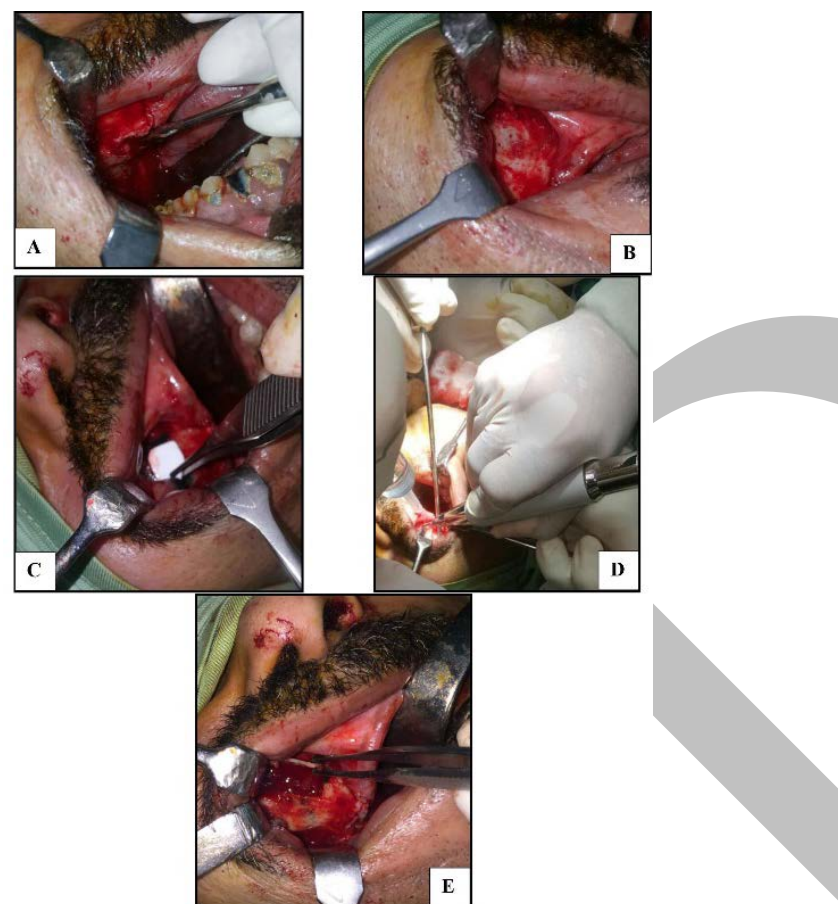

Figure (3): (A) Excision of the fistula tract by blade no 11. (B) Elevation of the flap and exposure of the bony defect. (C) We measure the size of the defect using suture paper as a template to know the size of the bone graft that we will harvest from the maxillary sinus wall. (D) Harvesting of the bone graft using the piezotome. (E) Bone graft after cutting.

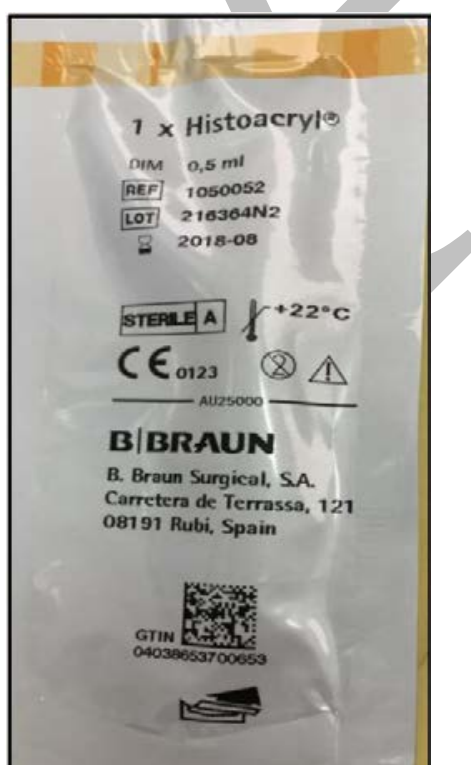

Figure (4) : Histoacryl used for fixation of bone graft.
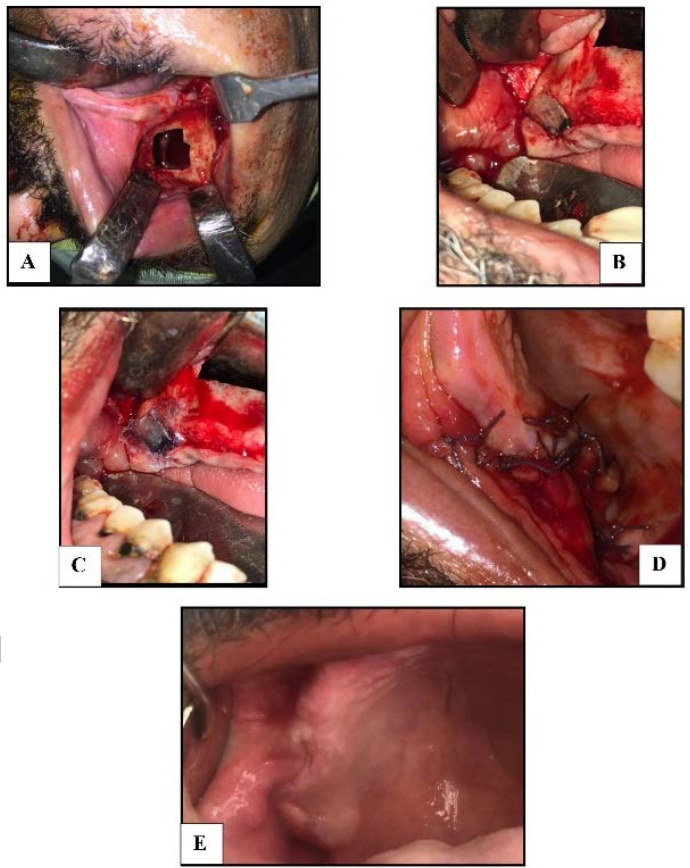

Figure (5): (A) Clear sinus after copious saline irrigation. (B) Press fitting the bone graft. (C) Fixing bone graft with histoacryl. (D) Suturing the flap. (E) Complete healing after 3 months.

\section{3-Post-operative care}

- Instructions were given to the patients to avoid sucking, nose blowing, sneezing and smoking.

- Application of ice packs to minimize edema first day after surgery, then shifting to hot fomentations till the edema subsided.

- Soft diet for one week at least.

- Maintaing good oral hygiene Povidone-iodine (Betadine U.S.P. 10 \% W/V. Manufactured by: the Nile Co for pharmaceuticals and Chemical industries Cairo - A.R.E. Licensed by Mundipharma AG -Basel - Switzerland) mouthwash every 8 hours daily for two weeks.

- Nasal decongestant Oxymetazoline (Afrin: manufactured by Afrin, Bayer Group Wuppertal-Barmen, Germany www.afrin.com) hydrochloride $0.05 \%$, three times daily for three days) to relief nasal obstructions and encourage drainage.

- Diclofenac sodium (Cataflam $50 \mathrm{mg}$ ): Manufactured by Novartis (Swiss multinational pharmaceutical company). as anti-inflammatory and analgesia (50mg, twice daily for one week).

- Broad spectrum antibiotic in the form of Amoxicillin $875 \mathrm{mg} /$ clavulanic acid $125 \mathrm{mg}$ (Augmentin1gm: GSK GlaxoSmitheKline, England) one tablet every 12 hours for seven days

- Antiedematous chymotrypsin \& trypsin (Alphintern: chymotrypsin 14 micro Katals and trypsin 5 micro katals) manufactured by: Amoun pharmaceuticals Egypt) to resolve any edema (one tablet every 8 hours for seven days).

\section{4-Follow up phase:}

\section{a-Clinical follow up}

After one week, clinical evaluation of dehiscence, bleeding, allergic reaction and infection

that may occur was done. Regular follow up for 4, 6, 8 weeks for evaluation of healing of the surgical wound, local 
allergic or inflammatory reaction, persistence of fluid and food escape from the nose or any undesired results that occured. Wound healing was evaluated using a scale from 1 to 4 (11). Score 1 is for complete healing, without dehiscence. Score 2 is for Incomplete healing, with minimal dehiscence. Score 3 is for non healed communications, with partial dehiscence. Score 4 is for open communication, with significant dehiscence.

\section{b-Radiographic follow up:}

After 12 weeks a CBCT was done to evaluate the integrity of the maxillary sinus wall and to evaluate closure of the fistula and amount of bone formation.

\section{Statistical analysis of the data}

Data was fed to the computer and analyzed using International Business Machines Statistical Package for the Social Sciences (IBM SPSS) software package version 20.0. (Armonk, NY: IBM Corp). Qualitative data were described using number and percent. Quantitative data were described using range (minimum and maximum), mean, standard deviation and median.

\section{The used tests were:}

\section{1- Chi-square test}

For categorical variables, to compare between periods.

\section{2- Post Hoc Test (Dunn's)}

To determine significant difference between periods.

\section{3- Wilcoxon signed ranks test}

For abnormally quantitative variables, to compare between two periods.

\section{RESULTS}

This study was performed on ten patients, including seven males and three females, who complained from post extraction oroantral fistulae. It was conducted in the Oral and Maxillofacial Surgery Department, Faculty of Dentistry, Alexandria University. The patients were selected according to inclusion and exclusion criteria for this study.

The age was ranging from 23 to 65 years old with mean age 41 years old. The cause of oroantral fistula was due to extraction of upper first molar in five patients (50\%), and extraction of upper second molar in the other five patients (50\%). The upper right quadrant was affected in three patients (30\%), while the upper left one was affected in the other seven patients (70\%).

The patients were examined immediately post-operative, after one week, 4 weeks, 6 weeks, 8 weeks and 12 weeks postoperatively. The following criteria were examined:

\section{Post-operative edema}

In all patients, the edema was only observed immediate postoperatively and disappeared after the first postoperative week.

\section{Post-operative bleeding}

There was no bleeding observed in the patients postoperatively.

\section{Post-operative infection}

During the first postoperative week, one patient had infection in the surgical site which was treated by antibiotic. The fistula did not heal and the infection persisted as pus discharged through the fistula with exposure of the bone graft.

Infection was present 4 weeks postoperatively in another two patients and treated by antibiotic. The fistula healed but the bone graft was exposed and removed. (Table 1).
Table 1: Distribution of the study group according to postoperative infection $(\mathrm{n}=10)$.

\begin{tabular}{|c|c|c|c|c|c|c|c|c|c|c|c|c|}
\hline \multirow{2}{*}{ Infection } & \multicolumn{2}{|c|}{ Immediate } & \multicolumn{2}{|c|}{$\begin{array}{l}\text { First } \\
\text { week }\end{array}$} & \multicolumn{2}{|c|}{$\begin{array}{c}4^{\text {th }} \\
\text { weeks }\end{array}$} & \multicolumn{2}{|c|}{$\begin{array}{c}\mathbf{6}^{\text {th }} \\
\text { weeks }\end{array}$} & \multicolumn{2}{|c|}{$\begin{array}{c}8^{\text {th }} \\
\text { weeks }\end{array}$} & \multicolumn{2}{|c|}{$\begin{array}{c}12^{\text {th }} \\
\text { weeks }\end{array}$} \\
\hline & No. & $\%$ & No. & $\%$ & No. & $\%$ & No. & $\%$ & No & $\%$ & No. & $\%$ \\
\hline Negative & 10 & 100.0 & 9 & 90.0 & 8 & 80.0 & 9 & 90.0 & 10 & 100.0 & 10 & 100.0 \\
\hline Positive & 0 & 0.0 & 1 & 10.0 & 2 & 20.0 & 1 & 10.0 & 0 & 0.0 & 0 & 0.0 \\
\hline
\end{tabular}

IV. Local allergic and inflammatory reaction

No patients had allergic or inflammatory reaction post operatively.

\section{Post-operative wound healing (Table 2)}

Closure of the wound was recorded in the first postoperative week, along with the 4th, 6th 8th and 12th week. This was done according to a score from 1 to 4 , one being completely healed and four has significant dehiscence.

The average score for healing was $2.4 \pm 0.7$ after the first postoperative week, with a decrease in the score at the end of fourth week to $1.8 \pm 0.63$. A minimal decrease of the score at the sixth week to $1.1 \pm 0.32$ and the same after 8 weeks ending with a minimal decrease at the 12 th week $1.0 \pm 0.0$. There was significant difference between the different time periods in our study.

Table 2: Evaluation of the study group according to wound healing. $(\mathrm{n}=10)$.

\begin{tabular}{||c|c|c|c|c|c||}
\hline $\begin{array}{l}\text { Wound } \\
\text { Healing }\end{array}$ & $\begin{array}{l}\mathbf{1}^{\text {st }} \\
\text { week }\end{array}$ & $\begin{array}{c}\mathbf{4}^{\text {th }} \\
\text { weeks }\end{array}$ & $\begin{array}{c}\mathbf{6}^{\text {th }} \\
\text { weeks }\end{array}$ & $\begin{array}{c}\mathbf{8}^{\text {th }} \\
\text { weeks }\end{array}$ & $\begin{array}{c}\mathbf{1 2}^{\text {th }} \\
\text { weeks }\end{array}$ \\
\hline Min. - Max. & $\begin{array}{c}2.0- \\
4.0\end{array}$ & $1.0-3.0$ & $1.0-2.0$ & $1.0-2.0$ & $1.0-1.0$ \\
Mean \pm SD. & $\begin{array}{c}2.40 \pm \\
0.70\end{array}$ & $\begin{array}{c}1.80 \pm \\
0.63\end{array}$ & $\begin{array}{c}1.10 \pm \\
0.32\end{array}$ & $\begin{array}{c}1.10 \pm \\
0.32\end{array}$ & $1.0 \pm 0.0$ \\
Median & 2.0 & 2.0 & 1.0 & 1.0 & 1.0 \\
\hline P & & 0.189 & $0.001^{*}$ & $0.001^{*}$ & $0.001^{*}$ \\
\hline
\end{tabular}

p: $\mathrm{p}$ value for Chi square for Friedman test for comparing between $1^{\text {st }}$ week and each other period, Sig. bet. periods was done using Post Hoc Test (Dunn's)

*: Statistically significant at $\mathrm{p} \leq 0.05$

\section{Persistence of fluid and food regurgitation from the} nose

One patient complained of persistence of fluid and food regurgitation from the nose but the others did not.

\section{VII.Radiographic results (Table 3 )}

When considering the size of the oroantral defect at the level of the sinus floor, there was significant bone formation according to the measurements of the preoperative and after 3 months postoperative CBCT (Figure 6). The mean of bone defect size preoperatively was $10.16 \pm 3.39 \mathrm{~mm}$ and it decreases to reach $7.76 \pm 4.1 \mathrm{~mm}$ after 3 months. The mean of the amount bone formed was $2.4 \pm 2.13 \mathrm{~mm}$. The $\mathrm{p}$ value for Wilcoxon signed ranks test for comparing between preoperative and after 3 months was statistically significant at $\mathrm{p} \leq 0.05$. 


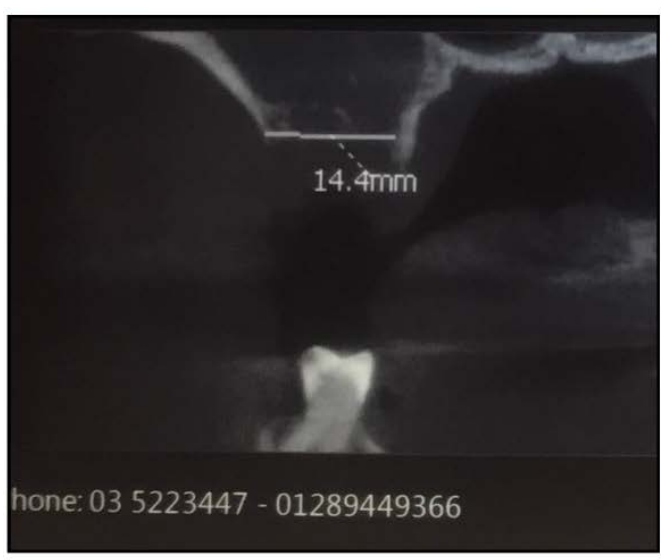

(A)

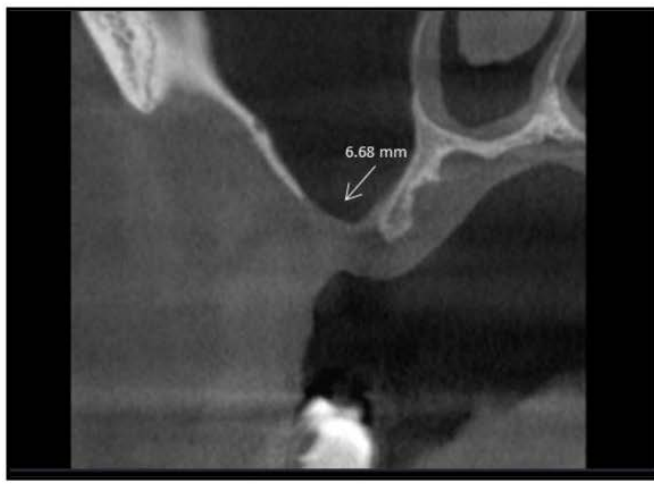

(B)

Figure (6): (A) Preoperative CBCT showing oroantral bony defect following extraction of right maxillary second molar with complete sinus opacity. (B) Postoperative CBCT after 3 months showing the amount of bone formation and clear sinus.

Table 3: Assessment of the study group according to bone defect size $(\mathrm{mm}$.) and amount of bone formation $(n=10)$.

\begin{tabular}{|c|c|c|c||}
\hline $\begin{array}{l}\text { Bone defect size } \\
(\mathbf{m m} .)\end{array}$ & $\begin{array}{c}\text { Pre- } \\
\text { operative }\end{array}$ & $\begin{array}{c}\text { After } 3 \\
\text { months }\end{array}$ & $\begin{array}{c}\text { Amount of bone } \\
\text { formation }\end{array}$ \\
\hline Min. - Max. & $5.90-14.80$ & $4.0-14.20$ & $0.0-6.0$ \\
Mean \pm SD. & $10.16 \pm 3.39$ & $7.76 \pm 4.10$ & $2.40 \pm 2.13$ \\
Median & 10.60 & 6.0 & 2.30 \\
\hline P & \multicolumn{2}{|c|}{$0.012^{*}$} & \\
\hline
\end{tabular}

According to these results, three cases (30\%) had failure and exposure of the bone graft, while the other seven patients (70\%) had successful outcomes with stable bone graft and closure of the oroantral fistula with no complications.

\section{DISCUSSION}

Many factors had been discussed by many authors when dealing with oroantral fistulae regarding the age, sex, etiology, related teeth, fistula size surgical techniques and radiographic findings.

According to gender distribution there was male predilection with $70 \%$ males and $30 \%$ females in our study group. The male to female ratio was 2.4:1. Other studies such as Delgado Galindez et al in 2005 (12) reported that male to female ratio was1.4:1. The study of Hirata et al in
2001 (13) showed that the rate of oroantral fistula is significantly higher in males with a male to female ratio of 1.7:1. Another study performed by Arbi in 2006(14) showed results similar to our study. This can be attributed to more common and traumatic tooth extraction in men. However, a study done by Yabroudi \& Dannan in 2008 (15) showed that there is equal distribution in oroantral fistulae incidence between males and females.

The age distribution observed in our study mainly is in the fourth decade of life with the mean age of 41 years. This is similar to a study done by Arbi in 2006 (14) who showed the same age group with highest incidence in the 4th decade - A clinical study by Guven in 1998 (16) showed that oroantral fistula most frequently occurs after the third decade of life. It is considered that the loss of teeth in association with advancing age increase the likelihood of fistula formation. Also the maxillary sinus reaches its greatest size during the third decade of life, so the incidence of oroantral communications expected to be higher after that. The risk of occurrence of oroantral communications in children and adolescent is reduced because of the relatively small size of the sinus at that age group (16). None of the patients in this study was younger than 20 years old.

Many causes can lead to oroantral fistula formation but the most common one is after dental extraction, especially the upper first molar, followed by the upper second molar. In our study group, oroantral fistula occurred after extraction of maxillary first molar in $50 \%$ of the patients followed by equal percentage of maxillary second molar. And these results are different from Hasegawa et al in 2016 (17), Von Wovern in 1982 (7) and Hernando et al in 2010 (18) which showed that extraction of the upper first molars is the most common etiologic factor for oroantral communications.

Regarding side involvement, oroantral fistula was found in $30 \%$ of the patients of the study group at the right side and $70 \%$ of the patients on the left side. Similarly, according to Abuabara et al in 2006 (19). left side predominates in the development of oroantral fistula with $51 \%$ which is similar to our results in this study

Successful closure of oroantral fistulae is challenging and many authors reported specific criteria for surgical procedures. Khandelwal \& Hajira in 2017 (20) considered three factors in the success of any flap operation performed for the closure of oroantral fistula including adequate vascularization of the flap, diversion of the antral secretion into nose and antrum must be free of infection.

Another study done by Von Wowern (7) concluded that elimination of sinus infection, excision of fistulous tract and proper postoperative care could eliminate maxillary sinusitis and decrease risk of failure after closure. In our study, preparation for surgery was done in all patients by copious irrigation using antiseptic mouthwash through the fistula and antibiotic description. This was done according to recommendations provided by authors, $(7,20)$ stating that the control of infection prior to and after surgery is the most important role for management of oroantral fistulae. However, one patient from the study group had infection in the first week postoperative and the infection persisted till the end of the 4th week postoperatively and 2 patients had infection four weeks postoperatively and then the infection subsided at the end of the 8th week postoperatively. The cause of failure could be attributed to improper management 
of infection preoperatively and not following the oral hygiene instructions postoperatively.

The incidence of maxillary sinusitis related to the oroantral fistulae pre-operatively in this study seems to be high, and this could be reflected to the high percentage of patients suffered from signs and symptoms of maxillary sinusitis. All patients in the study group suffered from pain, tenderness over the cheek, unilateral headache and nasal obstruction. While the presence of polypoid proliferation was found in $20 \%$ of the patients of the study group. This is similar to results of Watzak et al in 2005(6) that reported maxillary sinusitis with $50 \%$ to $60 \%$ of the patients.

Regarding the fistula size Von Wovern (7) concluded that spontaneous closure of an oroantral fistula of any size was rare, and that surgery was required for closure. However, studies done by Guven (16) and Abuabara et al (19), found that fistula smaller than $2 \mathrm{~mm}$ tended to close, contrary to fistula larger than $5 \mathrm{~mm}$. All the oroantral fistulae included in our study were long standing chronic fistulae and larger than $5 \mathrm{~mm}$ in the clinical widest diameter which were indicated for surgical closure.

In our study we used the buccal advancement flap in all the patients to cover the bone graft and the fistulae and we observed great success of the flap with minimal scarring and minimal reduction of the buccal sulcus after 3 months postoperatively that couldn't interfere with any prosthetic rehabilitation.

Disadvantages of the Rehrmann's method include the risk of reduction of the buccal sulcus depth and soft tissue scarring. A prospective follow-up study by Von Wowern (7) demonstrated that the reduction of sulcus depth after Rehrmann's method is permanent in half of the cases. However, Eneroth and Mortensson in 1996 (21) showed that the reduced depth of the sulcus to be a temporary problem.

Proctor in 1969 (3) used iliac cancellous bone graft for closure of large oroantral fistulae. The demand for implant rehabilitation is considered the main cause for selection of bone graft technique for closure. However, this technique has disadvantages of lengthening the surgical time and the need of second surgical site. We thought that we can use the buccal antrostomy wall after cald-well luc procedure as a bone graft with no donor site morbidity gaining the advantages of bone grafts as the closure of the fistula will be double layered and allowing further sinus augmentation for implant placement to be done easily .However, we had three failures in our cases with exposure of the bone graft. This could be attributed to the instability of the bone graft, persistent infection or not following postoperative instructions by the patients.

In our study, we used autogenous bone graft from the same site of surgery and fixed it with N-Butyl cyanoacrylate which is Histoacryl. We harvested the graft using piezotome which facilitated harvesting the desired size of the graft. Also buccal advancement flap was a flap of choice in this study for its simplicity, wide range of indications, and being the most commonly used by clinicians (19). By this technique, double layer closure was achieved which proved successful results.

Tissue biocompatibility was achieved in all patients in the study group. Otherwise, no other inflammatory reaction was observed after application of the histoacryl.

Cone beam computed tomography was chosen in our study as it overcomes the limitations of the other radiographic techniques which include variable magnification, distortion, and superimposition of structures (22). It was observed that there was a great difference between the two periods preoperative and 3 months postoperative regarding the amount of bone formation. The amount of bone formed in the study group was significant according to the statistical analysis of our results and this could be attributed to the presence of the autogenous bone graft that was harvested from the buccal antrostomy wall. However, in the three failure cases, the fistulae healed eventually but with no bone formation observed on the CBCT.

\section{CONCLUSION}

According to the results of the present study, it is concluded that the use of the buccal antrostomy wall as a bone graft fixed with $\mathrm{N}$ butyl cyanoacrylate proved satisfactory results in closure of large oroantral fistulae.

\section{CONFLICT OF INTEREST}

The authors declare that they have no conflicts of interest.

\section{REFERENCES}

1-Ogunsalu C. A new surgical management for oro-antral communication: the resorbable guided tissue regeneration membrane-bone substitute sandwich technique. West indian medical journal. 2005;54:261-3.

2-Hassan O, Shoukry T, Raouf AA, Wahba H. Combined palatal and buccal flaps in oroantral fistula repair. Egyptian Journal of Ear, Nose, Throat and Allied Sciences. 2012;13:77-81.

3-Proctor B. Bone graft closure of large or persistent oromaxillary fistula. Laryngoscope. 1969;79:822-6. Quoted from: Abdelhamid AN, Youssef T. Large oroantral fistula repair using combined buccal and palatal flaps: a case series. Egypt J Otolaryngol. 2018;34:48-54.

4-Joshi A, Kostakis GC. An investigation of post-operative morbidity following iliac crest graft harvesting. Br Dent J. 2004;196:167-71.

5-Nkenke E, Radespiel-Troger M, Wiltfang J, SchultzeMosgau S, Winkler G, Neukam FW. Morbidity of harvesting of retromolar bone grafts: a prospective study. Clin Oral Implants Res. 2002;13:514-21.

6-Watzak G, Tepper G, Zechner W, Monov G, Busenlechner $D$, Watzek G. Bony press- t closure of oroantral fistulae: a technique for pre-sinus lift repair and secondary closure. J Oral Maxillofac Surg. 2005;63:1288-94.

7-Von Wowern N. Closure of oroantral fistula with buccal flap: Rehrmann versus Môczár. Int J Oral Surg. 1982;11:156-65. Quoted from: Bhatt R, Barodiya A, Singh S, Awasthi N. Comparison between pedicled buccal fat pad flap and buccal advancement flap for closure of oroantral communication. J Appl Dent Med Sci. 2018;4:55-62.

8-Shermak MA, Wong L, Inoue N, Crain BJ, Im MJ, Chao EY, - Fixation of the craniofacial skeleton with butyl-2cyanoacrylate and its effects on histotoxicity and healing. Plast Reconstr Surg. 1998;102:309-18.

9-Foresta E, Torroni A, Gasparini G, Saponaro G, Longo G, Boniello R, et al. Use of N-butyl-2-cyanoacrylate (Glubran2®) in fractures of orbital-maxillo-zygomatic complex. J Oral Maxillofac Surg. 2015;14:761-4. 
10-El-Fattah HA, Nour YA, El-Daly A. Endoscopic radical antrectomy: a permanent replacement for the Caldwell-Luc operation. J Laryngol Otol. 2008;122:268-76.

11-Jovanović G, Burić N, Tijanić $M$. Stimulation of mucoperiostal slice epithelization by small power laser after the primary plastic of oroantral communication. Medicinski pregled. 2010;63:188-93.

12-Delgado Galindez B, Gonzalez Sanchez OJ, Villalpando Carrcon M, Albores Zuniga D. Surgical correction of oroantral fistulae with integration of mandibular bone. Rev Med Inst Mex Seguro Soc. 2005;43:167-72.

13-Hirata Y, Kino K, Nagaoka S, Miyamoto R, Yoshi-masu H, Amagasa T. A clinical investigation of oro-maxillary sinus perforation due to tooth extraction. Kokubyo Gkkizasshi. 2001;68:249-53.

14-Arbi E, Saleh M. management of an oroantral fistula-a clinical study of 30 cases. Pak oral dent j. 2006;26:55-8.

15-Yabroudi F, Dannan A. A comparison between submucosal connective tissue palatal flap and conventional pedicle palatal flap for the closure of oroantral fistulae. Internet $\mathrm{J}$ Dent Sci. 2008;8:24-7

16-Guven O. A clinical study on oroantral fistulae. J Craniomaxillofac Surg. 1998;26:267-71.

17-Hasegawa T, Tachibana A, Takeda D, Iwata E, Arimoto S, Sakakibara A, et al. Risk factors associated with oroantral perforation during surgical removal of maxillary third molar teeth. Oral Maxillofac Surg. 2016;20:369-75.

18-Hernando J, Gallego L, Junquera L, Villarreal P. Oroantral communications. A retrospective analysis. Med Oral Patol Oral Cir Bucal. 2010;15:499-503.

19-Abuabara A, Cortez AL, Passeri LA. de Moraes M, Moreira RW. Evaluation of different treatments for oroantral/oroanasal communications: experience of 112 cases. Int J Oral Maxillofac Sur. 2006;35:155-8.

20-Khandelwal P, Hajira N. Management of oro-antral communication and fistula: various surgical options. World journal of plastic surgery. 2017;6(1):3.

21-Eneroth CM, Mortensson G. Closure of antro-alveolar fistulae. Acta Otolaryngol. 1996;53:447-57.

22-Ahmad M, Jenny J, Downie M. Application of cone beam computed tomography in oral and maxillofacial surgery. Aust Dent J. 2012;57:82-94. 